\title{
Practical Exploration to High-skilled Talent Cultivation for Creative Industry under University and Enterprise Double-subject Mode
}

\author{
Jing $\mathrm{Fu}$ \\ Wuhan University of Media and Communications \\ Wuhan, China
}

\begin{abstract}
The paper conducts an analysis and discussion on creative talent development situation, university \& enterprise double-subject combination mode, and meaning and value of creative talent cultivation upon the mode under the background that local universities transit to technological universities to highlight local universities' reconsideration of talent cultivation mode and student cultivation objective for cultural creative industry. Certain creative thoughts and concepts on creative talent cultivation mode are proposed, which highlight the combination of universities and culture industry, education industry, subject development, and market development. Surrounding the practical teaching, the basic teaching theories emphasize openness and intersectionality regardless closeness and completeness, leading to a multidimensional study on talent cultivation of cultural creative industry.
\end{abstract}

Keywords-university-enterprise cooperation; double-subject; creation; talent cultivation; mode

\section{INTRODUCTION}

Being an emerging strategic industry, the cultural creative industry needs macro policies, creativity, and technological innovation. Moreover, the cultural creative products and services' cultural and technological content cannot be increased without talent and intelligent support from universities. With an internal logic between the creation function of universities and cultural creative industry, the universities can accumulate talent capital of cultural creative industry to promote the development of cultural creative industry and increase the cultural and technological content of culture creative industry. The mode of universityenterprise cooperation optimizes and upgrades the cultural creative industry upon the university-enterprise doublesubject by constructing incubation base in and out of universities for cultural creative industry.

Now, the provincial education bureau already encourages some universities to carry out transition and demands local regular universities to enhance practical teaching, improve in-school experiment and training and in-enterprise training and internship, and provide practical teaching over $40 \%$ in

This article is one of the research findings of the municipal university teaching research project of Wuhan City in 2015: Practical Exploration to High-skilled Talent Cultivation for Creative Industry under University \& Enterprise Double-subject --Taking the Course Mode "Design

Communication" for Example. (Project Number: 2015069) class teaching. Thus, compared to vocational colleges and comprehensive research institutions, applied technological universities must solve the problem of providing featured courses upon the market with due teaching effect.

\section{PROBLEM AND SitUATION OF DOMESTIC AND FOREIGN CULTIVATION MODE FOR CREATIVE INDUSTRY}

The concept of creative industry, proposed in England for the first time, is featured by strong creativity owned by creative talents. The creative industry in England advocates creation, which depends on intellectual property protection and integration of knowledge, culture, and economy. Creativity is the nature of creative industry, while only human resources can support the creativity. Thus, the sustainable development of creative industry relies on creative talent cultivation. English government pays great attention to cultivation of art talents in a complete art education system. Thus, among some professional institutions and associations funded by the government, more than $90 \%$ of institutions are equipped with art education. 330000 young people are included in the creative cooperation program, and about 3000 universities set art credits in subjects such as music, dance, drama, and art design.

America pays special attention to intellectual property protection in creative industry and regards the creative industry as the copyright industry. Focusing on the study of cultural management and cultivation of cultural management talents, "30 universities in America provide art management subject to cultivate high-quality cultural management talents including undergraduates, postgraduates, and PHD and substantially improve the management level of cultural science."

With a late starting compared to the developed country, China still seeks for a way to cultivate talents for creative industry in universities. Talents are cultivated and gathered in the creative industry parks of Shanghai as an example of talent cultivation practice of creative industry. Urban planning \& Decoration Planning Street, Chifeng Road, Yangpu District, Shanghai is the industry park based on talent strength of civil construction subject of Tongji University. Being a good growth carrier and space for 
creative enterprises, the park provides opportunities of knowledge sharing and talent exchange for various creative talents and facilitates the internship and practice for talent cultivations of universities.

However, many universities still need construct a systematic and scientific cultivation system, courses, and teachers directly related to the creative industry. Some experts mentioned, "The cultivation of creative talents is the premise and guarantee of creative industry development. Firstly, the creative industry, which just emerges, is short of industry talents and high-quality operation talents in the market. Secondly, the creative industry's big range and high cultural and technological content leads to high requirements on talents. Universities are main base for high-skilled talent cultivation. Thus, universities shall grasp the nature of creativity for creative industry when highlight profession and practice closely combining with the demand of creative industry development in local universities for talent cultivation practice of creative industry. During the process of integrating creative thought into talent cultivation, universities shall constantly stimulate student creativity and further complete a relatively steady high-skilled talent cultivation mode for creative industry with feature of applied technological universities.

Compared with those requirements, regular universities in China are poor in cultivation of students' vocational practice work ability. Especially, lack of practical teaching link in enterprises, regular universities fail to closely combine vocational practice with theoretical science. Thus, students fail to apply theoretical study into vocational practice. This is just the main training feature in foreign applied technological universities and the key for students to adapt to vocational work. Thus, during the whole cultivation process, students' practical teaching link is reflected in enterprise learning internship and production internship. The content arrangement inevitably leads to a greater difference in teaching effect.

\section{VALUE OF TALENT CULTIVATION FOR CREATIVE INDUSTRY UNDER UNIVERSITY-ENTERPRISE COOPERATION MODE}

The talent cultivation under university-enterprise mode focuses more on deep cooperation of teaching activities between universities and enterprises. With certain social and economic benefit upon mutual promotion, a positive teaching circulating system is constructed for green and fast talent cultivation path. It is very important to constantly improve the systematic talent cultivation pattern and system. Values therein are summarized as follows:

Firstly, the systematic university-enterprise practical teaching mode can facilitate students to better adapt to future job hunting as high-skilled applied technological talents oriented by cultural and education industry development and design and service market development in local universities.

Secondly, with certain reference value for course construction in design subject of other universities, the cognition of relevant design industry and universities can be improved. Students can better adapt to the industry and prepare for positions in work. The quality and quantity of graduates can also be improved.

Thirdly, the university-enterprise cooperation on industry, study, and research increases the practice ability and research ability of universities, enhances connection in and out of class, and transition from virtual practice to real employment. Thus, the design serves the society oriented by the market.

\section{Student on Talent Cultivation Mode FOR \\ CREATIVE INDUSTRY UNDER UNIVERSITY-ENTERPRISE DOUBLE-SUBJECT COOPERATION MODE}

The university-enterprise double-subject cooperation mode is well practiced in practical subject construction in the school. For example, the university-enterprise cooperation is applied as the practical teaching in Wuhan Xindi Advertising Co., Ltd. for Design Exchange course of visual communication design subject. Firstly, the university can express its strength in professional talent application and talent cultivation. Secondly, the enterprise can bring with the latest design concept, various fashion elements, and real projects of creative industry to stimulate students' creative potential and cultivate students' creative thinking. The study mainly includes the following aspects:

\section{A. Subject Course Teaching System Study}

The proportion of practical teaching hours in subject course will be more than $40 \%$ in applied technological universities. The first problem is the distribution of practical teaching hours in subject courses. The author believes that the distribution of practical link shall be with clear teaching objective similar to theoretical teaching and enhance the overall consideration of course arrangement upon the linkage of practical teaching hours and theoretical teaching hours in different stages.

\section{B. Subject Course Teaching Content Study}

According to the requirements of subject course teaching system, the tasks of practical teaching shall be formulated upon rationality and connection of teaching content. In this process, the difference of practical teaching link for students in different grades shall be made clear. How to include the university-enterprise teaching flexibly shall also be discussed to smoothly include enterprises in the teaching. Moreover, enterprises resources shall be integrated, so the students can work for the enterprises through the course.

\section{Subject course teaching supervision study}

The practical teaching link shall be arranged on student situation upon weekly teaching setting. In this teaching arrangement, how to supervise students' learning progress is critical to guarantee teaching quality. The concept of enterprise management can be introduced in the teaching supervision study of practical link. In this way, students can feel the work atmosphere in advance under guaranteed teaching. 
Thus, with an emphasis on the objective of high-skilled talent cultivation for creative industry, the universityenterprise cooperation teaching is included in the practical teaching of relevant courses from aspects including depth, mode, and evaluation of teaching content.

\section{DEVElopment TREnd of CREATIVE TALENT CULTIVATION IN FUTURE}

Design serves the society oriented by the market. Higher education and enterprises are community cannot be separated from each other upon mutual progress. Under the background that local universities transit into applied technological universities, the double-subject interactive talent cultivation mode can benefit for a good higher education environment, in which enterprises and universities contact, communication, and learn from each other. The creative talent cultivation in future shall be oriented by culture and education industry development and subject and market development. The talent cultivation development trend in long term includes the following points:

- more emphasis on cooperation mode between universities and enterprises. The enterprises can express more strength to make up the shortage of equipment and personal experience in universities. Meanwhile, the cooperation also makes for HR development and future development of enterprises.

- due adjustment in course setting and teaching arrangement. The adjustment in teaching mode of design practice course shall focus on application intersection and integration, enhance integration of course setting, increase enterprise internship time, import practical training project, enrich teaching content, and enhance students' practical ability and professional skill.

- available laws and regulations. The vocational education mode in England is based on its complete legal system. Without legal guarantee, enterprises cannot regard the education as its benefit and cannot guarantee the position, teacher, and training quality in teaching cooperation for successful internship.

\section{CONCLUSION}

The talent cultivation upon university-enterprise doublesubject cooperation mode provides a good carrier and platform for creative talent cultivation. Upon the proposal of university-enterprise double-subject creative talent cultivation, the analysis on content, design, implementation mode, and extension mode is conducted and some feasible plans are put forward. It is very meaningful to explore the practical teaching system study for higher grade courses of art design subject, enhance the openness and intersection of theoretical teaching and practical teaching, and strengthen the integrity and workability of course setting. How to supervise the university-enterprise teaching will be analyzed in future to guarantee the connection between enterprises and universities. Further exploration and thoughts will be proposed for the path for students' employment.

\section{REFERENCES}

[1] Zhang Wang. Study on Chinese Cultural Creative Industry Development [D]. Nanjing University, 2011.

[2] Zheng Guiyu. Thought of Art Design Talent Cultivation under Creative Industry Background [J]. China Academy of Art. 2010 (8).

[3] Zhao Shuming, Li Chengyu. Study on Creative Talent Cultivation Strategy [J]. Journal of Nanjing University (Philosophy, Literature, Social Science). 2006, (6).

[4] Hou Bo. Study on Cultural Creative Industry based on Resources Industry [D]. China University of Geosciences, 2009. 